\title{
Assessment of Clinical Effectiveness of Various Drugs in the Patients of Allergic Rhinitis visiting Tertiary Care Hospital of Punjab, India
}

\author{
${ }^{1}$ Gurpreet Kaur, ${ }^{2}$ Rachna Dhingra, ${ }^{3}$ Manjinder Singh
}

\begin{abstract}
Introduction: Allergic rhinitis is characterized by mild to severe upper respiratory symptoms, such as nasal congestion, rhinorrhea, sneezing, and itching. In this study, attempt is being made to evaluate the clinical efficacy of various drugs in allergic rhinitis and to compare clinical efficacy in individual symptom score of allergic rhinitis.
\end{abstract}

Materials and methods: Totally, 125 patients clinically diagnosed as suffering from allergic rhinitis were enrolled for the study. All the patients were randomly divided into five groups of 25 each. Patients were given tablet Montelukast $10 \mathrm{mg}$ once a day (OD) in group I, tablet Levocetirizine $5 \mathrm{mg}$ OD in group II, tablet Fexofenadine $180 \mathrm{mg}$ OD in group III, tablet Desloratadine $5 \mathrm{mg}$ OD in group IV, and tablet Chlorpheniramine maleate $4 \mathrm{mg}$ three times a day (TDS) in group V. Each patient was followed up after 2 weeks and then after 4 and 6 weeks for the sneezing and nasal congestion/obstruction.

Results: At the 2nd week follow-up, Levocetirizine was significantly effective with $40 \%$ patients having zero (0) sneezing symptom score and with mean rank 45.54 as compared with other drugs. At fourth and 6th week follow-up, Montelukast was more effective with 48 and $56 \%$ patients having zero sneezing symptom score and having mean rank 54.60 and 51.78 as compared with other drugs. At 2 nd week follow-up, Levocetirizine was significantly effective with $24 \%$ patients having zero symptom score; at 4th week follow-up, Montelukast was more effective with $44 \%$ patients having zero symptom score in nasal discharge; and at 6th week follow-up, Montelukast was more effective with $60 \%$ patients having zero symptom score.

Conclusion: Symptomatic improvement was seen in all the drug groups. It was observed that Levocetirizine was better at 2 weeks. Overall, at the end of 6 weeks of treatment, Montelukast group had maximum improvement followed by Levocetirizine, Fexofenadine, Desloratadine, and Chlorpheniramine respectively.

Keywords: Allergic rhinitis, Chlorpheniramine, Desloratadine, Fexofenadine, Levocetirizine, Montelukast.

${ }^{1}$ Senior Resident, ${ }^{2}$ Assistant Professor, ${ }^{3}$ Medical Officer

${ }^{1}$ Department of Plastic Surgery, Government Medical College Patiala, Punjab, India

2Department of ENT, Guru Gobind Singh Medical College \& Hospital, Faridkot, Punjab, India

${ }^{3}$ Department of Medicine, District Hospital, Patiala, Punjab, India

Corresponding Author: Rachna Dhingra, Assistant Professor Department of ENT, Guru Gobind Singh Medical College \& Hospital, Faridkot, Punjab, India, Phone: +918054733085 e-mail: shamim.monga2@gmail.com
How to cite this article: Kaur G, Dhingra R, Singh M. Assessment of Clinical Effectiveness of Various Drugs in the Patients of Allergic Rhinitis visiting Tertiary Care Hospital of Punjab, India. Clin Rhinol An Int J 2017;10(3):132-136.

\section{Source of support: Nil}

Conflict of interest: None

\section{INTRODUCTION}

Allergic rhinitis is a type-I allergic disorder of nasal mucosa characterized by mild to severe upper respiratory symptoms, such as nasal congestion, rhinorrhea, sneezing, and itching. Symptoms affecting the eyes and throat are also commonly associated with rhinitis. These symptoms arise from an underlying inflammatory process initiated by a reaction between the allergen and immunoglobulin E, neurogenic stimuli, and other complex processes. ${ }^{1}$ The treatment goal for allergic rhinitis is relief of symptoms. Therapeutic options available to achieve this goal include avoidance measures, oral antihistamines, intranasal corticosteroids, leukotriene receptor antagonists (LTRAs), and allergen immunotherapy. Other therapies that may be useful in select patients include decongestants and oral corticosteroids. ${ }^{2}$

$\mathrm{H}_{1}$-antihistamines are medications that block histamine at the $\mathrm{H}_{1}$-receptor level and comprise neutral antagonists or inverse agonists. Most $\mathrm{H}_{1}$-antihistamines also have additional antiallergic properties. New secondgeneration antihistamines are $\mathrm{H}_{1}$-receptor antagonists with high efficacy (rapid onset of action for allergic rhinitis symptoms, sometimes even on nasal congestion, improvement of quality of life, and additional antiallergic effects) and safety (low sedation rates). ${ }^{3}$

Montelukast is a cysteinyl-leukotriene receptor 1 antagonist that has been developed primarily for the treatment of bronchial asthma. Montelukast has been expected to be effective not only for the treatment of bronchial asthma but also for improvement of symptoms associated with allergic rhinitis based on its mechanism of action; its clinical development was initiated as a medication for allergic rhinitis. ${ }^{4}$

Since the introduction of cysteinyl-LTRA, initially as a medication for allergic lower airway disease, evidence regarding their effectiveness in allergic upper airway 
Clinical Effectiveness of Various Drugs in Allergic Rhinitis Patients

disease has been increasing. Montelukast, an LTRA and an antiasthmatic drug, was recently approved for clinical use in the treatment of allergic rhinitis through clinical studies performed in children and adults. ${ }^{5}$

In this study, attempt is being made to evaluate the clinical efficacy of various drugs in allergic rhinitis and to compare clinical efficacy in individual symptom score of allergic rhinitis.

\section{MATERIALS AND METHODS}

Totally, 125 patients attending the ear, nose, and throat outpatient department of Rajindra Hospital, Patiala, Punjab, India, were selected for this study. Patients were of varying age groups between 10 and 55 years, of either sex having clinically diagnosed as suffering from allergic rhinitis based on the characteristic history, corroborative physical findings, and blood eosinophilia. Patients with history of asthma, who underwent treatment with topical or systemic corticosteroids within 1 month, and with study drugs or decongestants within 1 week were excluded from the study. Informed consent was taken from the patient fulfilling the above criteria after explaining them about the type of study being carried out. All the patients were randomly divided into five groups of 25 each.

- Patients of group I were given tablet Montelukast $10 \mathrm{mg}$ OD

- Patients of group II were given tablet Levocetirizine $5 \mathrm{mg}$ OD

- Patients of group III were given tablet Fexofenadine $180 \mathrm{mg}$ OD

- Patients of group IV were given tablet Desloratadine $5 \mathrm{mg}$ OD

- Patients of group V were given tablet Chlorpheniramine maleate $4 \mathrm{mg}$ TDS
Table 1: Subjective assessment for the degree of relief of symptom score

\begin{tabular}{lllll}
\hline & \multicolumn{4}{c}{ Symptom score } \\
\cline { 2 - 5 } Symptoms & 0 & 1 & 2 & 3 \\
\hline Sneezing & No & $1-4$ & $5-9$ & $>10$ \\
Nasal congestion/obstruction & No & Mild & Moderate & Severe \\
\hline
\end{tabular}

Each patient was followed up after 2 weeks and then, after 4 and 6 weeks for the following parameters:

The subjective assessment for the degree of relief of symptoms was done according to total symptom score from 0 to 3 (Table 1).

0 No symptom

1 Mild

2 Moderate

3 Severe

The results were tabulated and analyzed by Chisquare, Kruskal-Wallis test.

\section{RESULTS}

According to Table 2, the incidence of allergic rhinitis was seen maximum in age group of 21 to 30 years (40\%) and very less in age group 51 to 60 years. Children below the age of 10 years were deliberately left out of the study for want of their cooperation in taking history. Youngest person in this study was 15 years and oldest was 55 years.

There were 73 males (58.4\%) and 52 females (41.6\%) in the study. Table 3 shows that the incidence of allergic rhinitis was slightly higher in males than in females.

Table 4 shows that housewives (28\%) are most affected by allergic rhinitis followed by farmers (23\%) and laborers (14.4\%). Housewives are probably most affected due to their greater exposure to various

Table 2: Distribution according to age

\begin{tabular}{lllllll}
\hline & \multicolumn{5}{c}{ Group } \\
\cline { 2 - 5 } Age in years & I Montelukast & II Levocetirizine & III Fexofenadine & IV Desloratadine & V CPM & Total \\
\hline$\leq 20$ & $5(20 \%)$ & $5(20 \%)$ & $9(36 \%)$ & $3(12 \%)$ & $4(16 \%)$ & $26(20.8 \%)$ \\
$21-30$ & $5(20 \%)$ & $10(40 \%)$ & $12(48 \%)$ & $9(36 \%)$ & $15(60 \%)$ & $51(40 \%)$ \\
$31-40$ & $8(32 \%)$ & $6(24 \%)$ & $0(0 \%)$ & $7(28 \%)$ & $4(16 \%)$ & $25(20 \%)$ \\
$41-50$ & $5(20 \%)$ & $2(8 \%)$ & $2(8 \%)$ & $4(16 \%)$ & $1(4 \%)$ & $14(11.2 \%)$ \\
$51-60$ & $2(8 \%)$ & $2(8 \%)$ & $2(8 \%)$ & $2(8 \%)$ & $1(4 \%)$ & $9(7.2 \%)$ \\
\hline Total & 25 & 25 & 25 & 25 & 25 & 125 \\
\hline
\end{tabular}

Table 3: Distribution of cases according to gender

\begin{tabular}{llllllll}
\hline & & \multicolumn{5}{c}{ Group } & \\
\cline { 3 - 7 } & & I Montelukast & II Levocetirizine & III Fexofenadine & IV Desloratadine & V CPM & Total \\
\hline Sex & Female & $7(28 \%)$ & $10(40 \%)$ & $10(40 \%)$ & $14(56 \%)$ & $11(44 \%)$ & $52(41.6 \%)$ \\
& Male & $18(72 \%)$ & $15(60 \%)$ & $15(60 \%)$ & $11(44 \%)$ & $14(56 \%)$ & $73(58.4 \%)$ \\
\hline Total & 25 & 25 & 25 & 25 & 25 & 125 \\
\hline
\end{tabular}


Table 4: Distribution of cases according to occupation

\begin{tabular}{|c|c|c|c|c|c|c|c|}
\hline & & \multicolumn{5}{|c|}{ Group } & \multirow[b]{2}{*}{ Total } \\
\hline & & I Montelukast & II Levocetirizine & III Fexofenadine & IV Desloratadine & V CPM & \\
\hline \multirow[t]{11}{*}{ Occupation } & Business & $0(0 \%)$ & $1(4 \%)$ & $4(16 \%)$ & $2(8 \%)$ & $2(8 \%)$ & $9(7.2 \%)$ \\
\hline & Cook & $1(4 \%)$ & 0 & 0 & 0 & 0 & $1(.8 \%)$ \\
\hline & Engineer & $1(4 \%)$ & 0 & 0 & 0 & 0 & $1(.8 \%)$ \\
\hline & Laborer & $7(28 \%)$ & $2(8 \%)$ & $2(8 \%)$ & $2(8 \%)$ & $5(20 \%)$ & $18(14.4 \%)$ \\
\hline & Housewife & $5(20 \%)$ & $7(28 \%)$ & $4(16 \%)$ & $10(40 \%)$ & $9(36 \%)$ & $35(28 \%)$ \\
\hline & Student & $2(8 \%)$ & $3(12 \%)$ & $1(4 \%)$ & $1(4 \%)$ & $2(29 \%)$ & $9(7.2 \%)$ \\
\hline & Painter & $1(4 \%)$ & 0 & 0 & 0 & 0 & $1(.8 \%)$ \\
\hline & Service & $3(12 \%)$ & $5(20 \%)$ & $5(20 \%)$ & $4(16 \%)$ & $1(4 \%)$ & $18(14.4 \%)$ \\
\hline & Farmer & $3(12 \%)$ & $7(28 \%)$ & $7(28 \%)$ & $6(24 \%)$ & $6(24 \%)$ & $29(23.2 \%)$ \\
\hline & Tailor & $1(4 \%)$ & 0 & $1(4 \%)$ & 0 & 0 & $2(1.6 \%)$ \\
\hline & Teacher & $1(4 \%)$ & 0 & $1(4 \%)$ & 0 & 0 & $2(1.6 \%)$ \\
\hline
\end{tabular}

Table 5: Comparison of sneezing symptom score from day 1 to 6 weeks follow-up in five groups

\begin{tabular}{|c|c|c|c|c|c|c|c|}
\hline & \multirow{2}{*}{$\begin{array}{l}\text { Symptom } \\
\text { score }\end{array}$} & \multicolumn{5}{|c|}{ Group } & \multirow[b]{2}{*}{ Total } \\
\hline & & I Montelukast & II Levocetirizine & III Fexofenadine & IV Desloratadine & $V C P M$ & \\
\hline \multirow{6}{*}{$\begin{array}{l}\text { Sneezing at day } 1 \\
\text { presentation }\end{array}$} & 1 & $4(16 \%)$ & $4(16 \%)$ & $4(16 \%)$ & $4(16 \%)$ & $4(16 \%)$ & $20(16 \%)$ \\
\hline & 2 & $12(48 \%)$ & $12(48 \%)$ & $12(48 \%)$ & $12(48 \%)$ & $12(48 \%)$ & $60(48 \%)$ \\
\hline & 3 & $9(36 \%)$ & $9(36 \%)$ & $9(36 \%)$ & $9(36 \%)$ & $9(36 \%)$ & $45(36 \%)$ \\
\hline & Total & 25 & 25 & 25 & 25 & 25 & 125 \\
\hline & Mean rank & 63 & 63 & 63 & 63 & 63 & \\
\hline & Sig. \# & \multicolumn{6}{|c|}{ Chi-square $0.000 ; p$-value 1.000; Nonsignificant } \\
\hline \multirow{6}{*}{$\begin{array}{l}\text { Sneezing at } 2 \\
\text { weeks follow-up }\end{array}$} & 0 & $8(32 \%)$ & $10(40 \%)$ & $5(20 \%)$ & $4(16 \%)$ & $2(8 \%)$ & $29(23.2 \%)$ \\
\hline & 1 & $12(48 \%)$ & $13(52 \%)$ & $12(48 \%)$ & $12(48 \%)$ & $11(44 \%)$ & $60(48 \%)$ \\
\hline & 2 & $5(20 \%)$ & $2(8 \%)$ & $8(32 \%)$ & $9(36 \%)$ & $12(48 \%)$ & $36(28.8 \%)$ \\
\hline & Total & 25 & 25 & 25 & 25 & 25 & 125 \\
\hline & Mean rank & 54.86 & 45.54 & 65.96 & 69.66 & 78.98 & \\
\hline & Sig. \# & \multicolumn{6}{|c|}{ Chi-square $15.174 ;$ p-value 0.004 ; Significant } \\
\hline \multirow{6}{*}{$\begin{array}{l}\text { Sneezing at } 4 \\
\text { weeks follow-up }\end{array}$} & 0 & $11(44 \%)$ & $12(48 \%)$ & $7(28 \%)$ & $8(32 \%)$ & $3(14.3 \%)$ & $41(33.9 \%)$ \\
\hline & 1 & $14(56 \%)$ & $13(52 \%)$ & $18(72 \%)$ & $17(68 \%)$ & $17(81 \%)$ & $79(65.3 \%)$ \\
\hline & 2 & $0(0 \%)$ & $0(0 \%)$ & $0(0 \%)$ & $0(0 \%)$ & $1(4.8 \%)$ & $1(0.8 \%)$ \\
\hline & Total & 25 & 25 & 25 & 25 & 21 & 121 \\
\hline & Mean rank & 54.60 & 52.20 & 64.20 & 61.80 & 74.33 & \\
\hline & Sig. \# & \multicolumn{6}{|c|}{ Chi-square 8.292; p-value 0.81 ; Nonsignificant } \\
\hline \multirow{5}{*}{$\begin{array}{l}\text { Sneezing at } 6 \\
\text { weeks follow-up }\end{array}$} & 0 & $16(64 \%)$ & $14(56 \%)$ & $11(44 \%)$ & $10(40 \%)$ & $8(38.1 \%)$ & $59(48.8 \%)$ \\
\hline & 1 & $9(36 \%)$ & $11(44 \%)$ & $14(56 \%)$ & $15(60 \%)$ & $13(61.9 \%)$ & $62(51.2 \%)$ \\
\hline & Total & 25 & 25 & 25 & 25 & 21 & 121 \\
\hline & Mean rank & 51.78 & 56.62 & 63.88 & 66.30 & 67.45 & \\
\hline & Sig. \# & \multicolumn{6}{|c|}{ Chi-square 4.759; p-value 0.313; Nonsignificant } \\
\hline
\end{tabular}

aeroallergens and food particles in the house as well as in the surroundings.

Table 5 shows that at 2 nd week follow-up Levocetirizine in group II is significantly effective with $40 \%$ patients having zero sneezing symptom score and with mean rank 45.54 as compared with other drugs. At 4 th and 6th week follow-up Montelukast in group I is more effective with 48 and $56 \%$ patients having zero sneezing symptom score and having mean rank 54.60 and 51.78 as compared with other drugs.

Table 6 shows that at 2nd week follow-up Levocetirizine in group II is significantly effective with $24 \%$ patients having zero (0) symptom score in nasal discharge/rhinor- rhea symptom and with mean rank 40.88 as compared with other drugs. At 4th week follow-up Montelukast in group I is more effective with $44 \%$ patients having zero symptom score in nasal discharge/rhinorrhea symptom and having mean rank 50.10. At 6th week follow-up Montelukast in group I is more effective with $60 \%$ patients having zero symptom score in nasal discharge/rhinorrhea symptom and having mean rank 50.00 .

\section{DISCUSSION}

Allergic rhinitis is one of the commonest problems met within the practice of ear, nose, and throat specialty. At the same time, the diagnosis and treatment of allergic 
Clinical Effectiveness of Various Drugs in Allergic Rhinitis Patients

Table 6: Comparison of nasal discharge/rhinorrhea symptom score from day 1 presentation to 6 weeks follow-up in five groups

\begin{tabular}{|c|c|c|c|c|c|c|c|}
\hline & \multirow{2}{*}{$\begin{array}{l}\text { Symptom } \\
\text { score }\end{array}$} & \multicolumn{5}{|c|}{ Group } & \multirow[b]{2}{*}{ Total } \\
\hline & & I Montelukast & I/ Levocetirizine & III Fexofenadine & IV Desloratadine & VCPM & \\
\hline \multirow{6}{*}{$\begin{array}{l}\text { Nasal discharge } \\
\text { at day } 1 \\
\text { presentation }\end{array}$} & 1 & $1(4 \%)$ & $2(8 \%)$ & $1(4 \%)$ & $1(4 \%)$ & $1(4 \%)$ & $6(4.8 \%)$ \\
\hline & 2 & $12(48 \%)$ & $14(56 \%)$ & $12(48 \%)$ & $12(48 \%)$ & $12(48 \%)$ & $62(49.6 \%)$ \\
\hline & 3 & $12(48 \%)$ & $9(36 \%)$ & $12(48 \%)$ & $12(48 \%)$ & $12(48 \%)$ & $57(45.6 \%)$ \\
\hline & Total & 25 & 25 & 25 & 25 & 25 & 125 \\
\hline & Mean rank & 64.70 & 56.20 & 64.70 & 64.70 & 64.70 & \\
\hline & Sig. \# & \multicolumn{6}{|c|}{ Chi-square 1.406; p-value 0.843; Nonsignificant } \\
\hline \multirow{6}{*}{$\begin{array}{l}\text { Nasal discharge } \\
\text { at } 2 \text { weeks } \\
\text { follow-up }\end{array}$} & 0 & $3(12 \%)$ & $6(24 \%)$ & $2(8 \%)$ & $2(8 \%)$ & $1(4 \%)$ & $14(11.2 \%)$ \\
\hline & 1 & $14(56 \%)$ & $18(72 \%)$ & $14(56 \%)$ & $14(56 \%)$ & $8(32 \%)$ & $68(54.4 \%)$ \\
\hline & 2 & $8(32 \%)$ & $1(4 \%)$ & $9(36 \%)$ & $9(36 \%)$ & $16(64 \%)$ & $43(34.4 \%)$ \\
\hline & Total & 25 & 25 & 25 & 25 & 25 & 125 \\
\hline & Mean rank & 61.34 & 40.88 & 65.20 & 65.20 & 82.38 & \\
\hline & Sig. \# & \multicolumn{6}{|c|}{ Chi-square 20.968; p-value 0.000; Significant } \\
\hline \multirow{6}{*}{$\begin{array}{l}\text { Nasal discharge } \\
\text { at } 4 \text { weeks } \\
\text { follow-up }\end{array}$} & 0 & $11(44 \%)$ & $10(40 \%)$ & $5(20 \%)$ & $4(16 \%)$ & $2(9.5 \%)$ & $32(26.4 \%)$ \\
\hline & 1 & $14(56 \%)$ & $15(60 \%)$ & $20(80 \%)$ & $21(84 \%)$ & $18(85.7 \%)$ & $88(72.7 \%)$ \\
\hline & 2 & $0(0 \%)$ & $0(0 \%)$ & $0(0 \%)$ & $0(0 \%)$ & $1(4.8 \%)$ & $1(.8 \%)$ \\
\hline & Total & 25 & 25 & 25 & 25 & 21 & 121 \\
\hline & Mean rank & 50.10 & 52.50 & 64.50 & 66.90 & 72.90 & \\
\hline & Sig. \# & \multicolumn{6}{|c|}{ Chi-square $12.161 ;$ p-value 0.016 ; Significant } \\
\hline \multirow{6}{*}{$\begin{array}{l}\text { Nasal discharge } \\
\text { at } 6 \text { weeks } \\
\text { follow-up }\end{array}$} & 0 & $15(60 \%)$ & $14(56 \%)$ & $8(32 \%)$ & $7(28 \%)$ & $7(33.3 \%)$ & $51(42.1 \%)$ \\
\hline & 1 & $10(40 \%)$ & $11(44 \%)$ & $17(68 \%)$ & $18(72 \%)$ & $13(61.9 \%)$ & $69(57 \%)$ \\
\hline & 2 & $0(0 \% 0$ & $0(0 \%)$ & $0(0 \%)$ & $0(0 \%)$ & $1(4.8 \%)$ & $1(.8 \%)$ \\
\hline & Total & 25 & 25 & 25 & 25 & 21 & 121 \\
\hline & Mean rank & 50.00 & 52.40 & 66.80 & 69.20 & 67.97 & \\
\hline & Sig. \# & \multicolumn{6}{|c|}{ Chi-square 9.153; p-value 0.057; Nonsignificant } \\
\hline
\end{tabular}

rhinitis has been a challenge to the ENT surgeon. A common man may ignore sneezing and running nose but it is a warning signal of the danger lying ahead and hence, must be investigated and treated accordingly. Thus, present study was undertaken to obtain observations to evaluate and compare the clinical efficacy of Montelukast, Chlorpheniramine maleate, Levocetirizine, Desloratadine, Fexofenadine and to find out antiallergic drug with maximum improvement in total symptom complex score.

The age of patients in all the five groups ranged from 15 to 55 years. The maximum number of patients $40 \%$ were found in the age group of 21 to 30 years. Durham ${ }^{6}$ reported that prevalence is low in very young children but rises to a plateau in teenagers and young adults and declines progressively with increasing age. Pawankar ${ }^{7}$ reported that symptoms peak in second, third, and fourth decades of life. The present study is in complete agreement with previous studies in pattern of age distribution and closely coincide with that of majority of authors as patient between 20 and 30 years comprised $40.8 \%$ of the total in our study. The reason for more number of patients in this age group may be attributed to the fact that young adults are more exposed to the external environment because of household, social, as well as professional responsibilities, hence, being more in contact to allergens.
Also this age group is expected to have early treatment seeking behavior than elderly and young children.

In the present study, incidence of allergic rhinitis was a little higher in males (58.4\%) as compared with females (41.6\%). There were 7 females and 18 males in group I, 10 females and 15 males in group II, 10 females and 15 males in group III, 14 females and 11 males in group IV, and 11 females and 14 males in group V. All the five groups were comparable to each other. Sibbald and Rink ${ }^{8}$ also reported the incidence to be higher in males than in females. The reason for this difference in sex incidence may be more in males due to their outdoor activities and hence, increased exposure to allergens.

According to the present study, highest incidence of allergic rhinitis was found in housewives (28\%). Farmers comprised $23.2 \%$ of the total. Students constituted $9 \%$ of the present study group. Higher incidence of allergic rhinitis in housewives and farmers could be expected by their almost continuous contact with innumerable allergens like pollen, grasses, various grains, wheat flour, and dust (house dust and field dust). Housewives also have to look after domestic animals and pets if they have any, especially in the rural areas. Students are also exposed to innumerable allergens during study or while playing. Mygind ${ }^{9}$ and Pawankar ${ }^{7}$ all identified house dust and house dust mite to be the most important allergen 
causing allergic rhinitis. Jones et $\mathrm{al}^{10}$ implicated house dust, animal emanations, perfumes, and cosmetics to be important as the causative factors leading to allergic rhinitis symptoms.

As a disease, allergic rhinitis is one of the most underestimated diseases, in terms of its impact, severity, treatment, and cost. From the patient perspective, having symptomatic allergic rhinitis means living with any or all of the symptoms of nasal congestion, headache, postnasal drip, repeated sneezing, runny nose, and other symptoms on a near-daily basis. Ocular symptoms are common, difficult to control, and have the greatest negative impact on patients' quality of life. The allergic rhinitis symptoms impair patients' function in day-to-day life and cause sleep disturbance, fatigue, absenteeism, and productivity loss at work and school. ${ }^{11}$

Sneezing is one of the most common symptoms of allergic rhinitis. Levocetirizine was associated with significant improvement in sneezing at 2 nd week followed by Montelukast, Fexofenadine, and Desloratadine. Chlorpheniramine maleate was least effective. At 4th week, Levocetirizine was slightly better than Montelukast followed by Desloratadine, Fexofenadine, and Chlorpheniramine maleate. At 6th week, effect of Montelukast was better than Levocetirizine followed by Fexofenadine, Desloratadine, and Chlorpheniramine maleate. Desloratadine and Fexofenadine were also similar in effect but less effective than Levocetirizine and Montelukast. Chlorpheniramine maleate was least effective drug in sneezing.

Regarding nasal discharge, Levocetirizine was significantly better than Montelukast at 2 weeks follow-up followed by Fexofenadine, which was better than Desloratadine and Chlorpheniramine maleate. At 4th week follow-up, Montelukast was more effective followed by Levocetirizine, Fexofenadine, Desloratadine, and Chlorpheniramine maleate. At the end of 6 weeks, Montelukast was more effective than Levocetrizine followed by Fexofenadine, Chlorpheniramine maleate, and Desloratadine. However, the difference was not significant.

First-generation antihistamines (diphenhydramine, chlorpheniramine, hydroxyzine, and brompheniramine) tend to reduce itching, sneezing, and rhinorrhea, with less impact on nasal congestion. They cause significant sedation, as they are lipophilic as they cross the bloodbrain barrier, so they are contraindicated in the treatment if the patient performs operator-dependent activities. The use of second-generation antihistaminics whose characteristic is to be lipophobic was developed to avoid the sedative effects on the central nervous system of the antihistamines of the first generation. The new antihistamines (desloratadine, fexofenadine, and levocetirizine) are effective in relieving the nasal congestion associated with allergic rhinitis. The effect begins as early as day 2 and is consistent and progressive throughout treatment. ${ }^{12}$

\section{CONCLUSION}

Incidence of allergic rhinitis was highest in 21 to 30 years of age. Symptomatic improvement was seen in all the drug groups. It was observed that Levocetirizine is better at 2 weeks. Overall at the end of 6 weeks of treatment Montelukast group had maximum improvement followed by Levocetirizine, Fexofenadine, Desloratadine, and Chlorpheniramine respectively.

\section{REFERENCES}

1. Singh-Franco D, Ghin HL, Robles GI, Borja-HartN, AlexandraP. Levocetirizine for the treatment of allergic rhinitis and chronic idiopathic urticaria in adults and children. Clin Ther 2009 Aug;31(8):1664-1687.

2. May, JR.; Smith, PH. Allergic rhinitis. In: Dipiro JT, Talbert RL Yee GC, Matzke GR, Wells BG, Posey ML, editors. Pharmacotherapy. A pathophysiologic approach. 7th ed. New York (NY): McGraw Hill; 2008. p. 1565-1575.

3. Mullol J. Positioning of antihistamines in the allergic rhinitis and its impact on asthma (ARIA) guidelines. Clin Exp Allergy Rev 2012 Mar;12(1):17-26.

4. Okubo K, Baba K. Therapeutic effect of montelukast, a cysteinyl leukotriene receptor 1 antagonist, on Japanese patients with seasonal allergic rhinitis. Allergol Int 2008 Sep;57(3): 247-255.

5. Cingi C, Gunhan K, Gage-White L, Unlu H. Efficacy of leukotriene antagonists as concomitant therapy in allergic rhinitis. Laryngoscope 2010 Sep;120(9):1718-1723.

6. Durham, S. Management update in rhinitis and nasal polyposis. Lisbon, Portugal. March 24-25, 1995.

7. Pawankar R. Allergic rhinitis and asthma from the link to emerging therapies. Indian J Chest Dis Allied Sci 2003 JulSep;45(3):179-189.

8. Sibbald B, Rink E. Epidemiology of seasonal and perennial rhinitis clinical presentation and medical history. Thorax 1991 Dec;46(12):895-901.

9. Mygind, N. Nasal allergy. Oxford: Blackwell Scientific Publications; 1978. p. 52-84.

10. Jones NS, Carney AS, Davis A. Prevalence of allergic rhinosinusitis: a review. J Otol Laryngol 1998 Nov;112(11):1019-1030.

11. Price DB, Scadding G, Bachert C, Saleh H, Nasser S, Carter V, von Ziegenweidt J, Durieux AM, Ryan D. UK prescribing practices as proxy markers of unmet need in allergic rhinitis: a retrospective observational study. NPJ Prim Care Respir Med 2016 Jun;26:16033.

12. Ramírez-Jiménez F, Pavón-Romero G, Juárez-Martínez LL, Terán LM. Allergic rhinitis. J Aller Ther 2012 May;S5:006. 